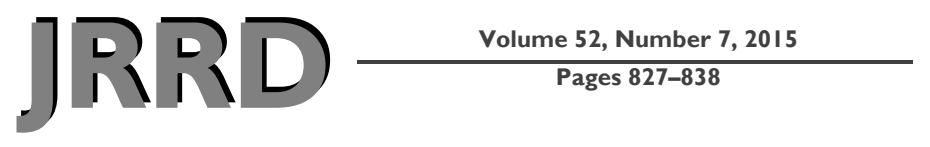

\title{
Lower-limb amputation and effect of posttraumatic stress disorder on Department of Veterans Affairs outpatient cost trends
}

\author{
Vibha Bhatnagar, MD, MPH; ${ }^{1 *}$ Erin Richard, MPH; ${ }^{1}$ Ted Melcer, PhD; ${ }^{2}$ Jay Walker, BS; ${ }^{2}$ Michael Galarneau, \\ MS, NREMT ${ }^{2}$ \\ ${ }^{1}$ Department of Family Medicine and Public Health, University of California, San Diego, La Jolla, CA; and Depart- \\ ment of Veterans Affairs San Diego Healthcare System, San Diego, CA; ${ }^{2}$ Medical Modeling, Simulation, and Mission \\ Support Department, Naval Health Research Center, San Diego, CA
}

\begin{abstract}
Department of Veterans Affairs (VA) outpatient costs were analyzed for combat Veterans injured in Iraq and Afghanistan from 2001 to 2008. Patients had serious lowerlimb injuries $(n=170)$ or unilateral $(n=460)$ or bilateral $(n=$ 153) lower-limb amputation(s). Total costs over the follow-up period (2003 to 2012) and annual costs were analyzed. Unadjusted mean costs per year in 2012 U.S. dollars were $\$ 7,200$, $\$ 14,700$, and $\$ 18,700$ for limb injuries and unilateral and bilateral lower-limb amputation(s), respectively $(p<0.001)$. Multivariate modeling indicated that annual cost declined after the first year in the VA for Veterans with limb injuries $(p<0.001$, repeated measures). In contrast, annual costs doubled after 3-5 years with unilateral $(p<0.001)$ and bilateral amputation(s) $(p<0.001)$. Among amputees, prosthetics comprised more than $50 \%$ of outpatient cost; unadjusted mean cost per year for prosthetics was 7-9 times higher in comparison with Veterans with limb injuries. Amputation status was associated with an adjusted 3.12-fold increase in mean prosthetic cost per year $(p<0.001$, general linear model). In addition, posttraumatic stress disorder (PTSD) was associated with increased prosthetic cost by amputation status $(p<0.001)$ and increased psychiatric and pharmacy costs (both $p<0.001$ ). Results indicate relatively high and sustained outpatient costs driven by prosthetics following amputation. Finally, PTSD affected cost for multiple domains of health, highlighting the importance of accurate diagnosis, treatment, and support for PTSD.
\end{abstract}

Key words: amputation, amputee, Department of Veterans Affairs, Expeditionary Medical Encounter Database, outpatient cost, pharmacy, posttraumatic stress disorder, prosthetic, psychiatry, rehabilitation, utilization.

\section{INTRODUCTION}

In the past decade, many U.S. Veterans have served through repeated deployments in Iraq and Afghanistan. Compared with previous wars, survival rates have improved because of advancements in body armor and battlefield medicine. The nature of these conflicts is also somewhat unique, characterized by blast injuries from improvised explosive devices [1], with high rates of posttraumatic stress disorder (PTSD), traumatic brain injury (TBI), and complex limb (arm and leg) injury often leading to amputation and/or reconstruction [1-12].

The rate of limb injuries requiring amputation among military personnel in Iraq and Afghanistan has remained

Abbreviations: AIS $=$ Abbreviated Injury Scale, $\mathrm{CI}=$ confidence interval, EMED = Expeditionary Medical Encounter Database, GLM = general linear model, ICD-9-CM = International Classification of Diseases-9th Revision-Clinical Modification, ISS = Injury Severity Score, LEAP = Lower Extremity Assessment Project, NHRC = Naval Health Research Center, PTSD = posttraumatic stress disorder, TBI = traumatic brain injury, VA = Department of Veterans Affairs.

*Address all correspondence to Vibha Bhatnagar, MD, MPH; Department of Family Medicine and Public Health, University of California, San Diego, 9500 Gilman Dr, MC 0725, La Jolla, CA 92093; 858-822-1233; fax: 858-5344642. Email: vbhatnag@ucsd.edu

http://dx.doi.org/10.1682/JRRD.2014.11.0288 
high, with more than 300 amputations in 2010 and 2011 [13]. The physical recovery from these injuries is especially long, often requiring extensive rehabilitation, limbreconstruction surgeries, orthotics, or prosthetics. Lowerlimb amputees usually required approximately 9-15 mo of outpatient rehabilitation at military facilities and reported an average of three prostheses following lowerlimb amputation to accommodate basic to specialized activities (e.g., walking vs running prostheses) [14]. Transition to civilian life can be especially difficult because of physical limitations as well as limited coping skills resulting from TBI, PTSD, and/or substance abuse [4]. PTSD is of particular interest because it is known to complicate rehabilitation following combat injury [2,1112,15-16]. Moreover, these Veterans have high disability rates, with 64 percent of personnel with limb injuries found unfit for Active Duty [17]. Similarly, Iranian Veterans with lower-limb amputation(s) from the Iran-Iraq war (1980-1988) had high rates of physical impairment and chronic pain more than $25 \mathrm{yr}$ after injury [18].

However, little is known about the long-term healthcare costs for American Veterans with limb amputations and serious limb injuries from the more recent conflicts in Iraq and Afghanistan. In this study, we used data from the Department of Veterans Affairs (VA) national database from 2003 to 2012 to study outpatient cost trends associated with caring for Veterans with combat-related lowerlimb amputations and limb injuries. We evaluated the effect of lower-limb injury, amputation(s), and PTSD on outpatient costs, adjusting for other combat-related covariates such as injury severity and number of deployments. We focused on outpatient costs for specific categories: psychiatry, pharmacy, prosthetics, and rehabilitation.

\section{METHODS}

\section{Data Sources}

This study was approved by the VA San Diego Research and Development Service; University of California, San Diego; and Naval Health Research Center (NHRC) Institutional Review Boards. The study cohort was identified from the Expeditionary Medical Encounter Database (EMED) maintained by the NHRC in San Diego, California. The EMED contains information abstracted from U.S. servicemembers' medical records completed by military health providers at forward-deployed treatment facilities in the combat zone, nearest to the point of injury. It is linked with inpatient and outpatient medical record information and tactical, personnel, operational, and deployment-related data obtained from other U.S. Department of Defense databases [19]. Records from each level of care are reviewed by certified nurse coders at NHRC and assigned codes from the International Classification of Diseases-9th RevisionClinical Modification (ICD-9-CM), Abbreviated Injury Scale (AIS) 2005 [20-21], and Injury Severity Score (ISS) coding systems. Additional patient information was provided by the VA Informatics and Computing Infrastructure and included data from the Corporate Data Warehouse, Vital Status file, and Decision Support System National Data Extracts for fiscal years 2003 through 2012 [22-23].

\section{Study Sample}

The initial study sample $(n=910)$ was identified from EMED and included military personnel serving in Iraq or Afghanistan between 2001 and 2008 with combat-related lower-limb amputation(s) or serious lower-limb injury with an AIS score $\geq 3$ without amputation [20-21]. Those with only digital or upper-limb amputation were not studied here. We were able to identify $837(92 \%)$ in the VA database ( $n=73$ missing VA data, including cost data). Of these, patients in the VA for $<1 \mathrm{yr}(n=54)$ were also excluded, resulting in the final cohort of Veterans studied here $(n=783)$, including those with lower-limb injury $(n=170)$, unilateral lower-limb amputation $(n=460)$, and bilateral lower-limb amputations $(n=153)$.

\section{Amputation Status and Covariates}

Amputation status was analyzed as an ordinal variable: (0) limb injury, no amputation; (1) unilateral lowerlimb amputation; or (2) bilateral lower-limb amputations. Other variables from the EMED included in the analysis were age at injury (as age was highly skewed, age was dichotomized by above or below upper quartile: $<27$ or $\geq 27 \mathrm{yr}$ ), number of deployments $(1,2,3$, or $\geq 4)$, injury mechanism (blast, gunshot, or other), and diagnosis of TBI. ISS was grouped into four categories: 0-9, 10-15, 16-25, and $>25$. We also coded Injury Year (2001-2005 vs 2006-2008) as a proxy for changes over time between 2001 and 2008 that may have influenced outcomes. For example, operational tempo increased during the military surge later in the Iraq conflict ( 2007). Also, this variable helps control for changes in recording or reporting bias for certain diagnoses because of increased awareness (e.g., PTSD) during the latter stages of the Iraq conflict. 
In addition, the following were extracted from the VA databases: a diagnosis of PTSD from the VA (at least two ICD-9-CM 309.81 diagnostic codes were required) and years within the VA system. Because inpatient hospitalization may indicate a more complex patient group requiring more outpatient services, this was also included as an exploratory variable. As only a minority of patients had an inpatient stay $(n=288)$, hospitalization was dichotomized (yes/no).

\section{Cost}

VA stop codes were used to identify specific types of services such as primary care, psychiatry, and pharmacy. Stop codes were then grouped into larger categories as defined by the VA Health Economic Resource Center [24]. For this analysis, we focused on total outpatient costs and four main cost categories: psychiatry, pharmacy, prosthetics, and rehabilitation. It is important to note that the prosthetics category consisted of durable medical equipment generally, including limb prosthetics, orthotics, and wheelchairs. Substance abuse treatment was grouped with psychiatry. Though not analyzed separately in this study, remaining outpatient services, including pain clinic, ancillary support services, diagnostic services, and surgery were categorized as "Other." For visits with a primary and secondary stop code, ICD-9CM diagnostic codes were reviewed. The majority of diagnostic codes corresponded to the primary stop code. Mental health services, however, were provided in several outpatient clinic settings. Therefore, secondary mental health stop codes were considered primary if there was an ICD-9-CM mental health diagnostic code (290$316)$ for that visit ( $1.3 \%$ of the observations). All costs were adjusted to 2012 dollars using the Gross Domestic Product implicit price deflator [25].

\section{Data Analysis}

Analyses were run in STATA version 10.0 (STATA Corporation; College Station, Texas) and SAS version 9.3 (SAS Institute Inc; Cary, North Carolina).

\section{Unadjusted Cost}

Total cost was tallied and divided by the years of follow-up to estimate total cost per year for each Veteran; these were then averaged to estimate mean total cost per person per year by amputation group (limb injury or unilateral or bilateral amputation). This was repeated for each cost category (psychiatry, pharmacy, prosthetics, and rehabilitation). In addition, all outpatient costs and costs for each clinic/service category were tallied for each Veteran by year after entry into the VA system to estimate annual cost for a specific year; these were also averaged to estimate mean annual cost per person for a specified year by amputation group. Because we were interested in how costs changed after entry into the VA, the analysis was not done by VA fiscal year. Therefore, costs for the first year reflect the outpatient costs for patients in their first year in the VA system.

\section{Adjusted Cost}

\section{Model Covariates}

Both years within the VA and Injury Year were colinear. Because we were primarily interested in servicerelated risk factors, only Injury Year was included in the multivariate analyses. There was also a high correlation with amputation status and mechanism of injury (blast injuries caused approximately $90 \%$ of amputations); therefore, mechanism of injury was not included in the final modeling. Thus, the following covariates were included in all models: amputation status, diagnosis of PTSD, diagnosis of TBI, age at injury, ISS (four categories as defined previously), number of deployments (1, 2, 3, or $\geq 4)$, Injury Year (2001-2005 vs 2006-2008), and inpatient VA hospital stay during the follow-up period (yes/no).

\section{Adjusted Annual Cost}

Multivariable regression models were used to examine how amputation status and other combat-related covariates (listed previously) contributed to outpatient cost. Annual costs for each Veteran were analyzed as a repeated variable from the first through eighth years in the VA using the generalized estimating equation approach (SAS GENMOD procedure), with a gamma distribution and log-link. An autoregressive covariance structure was chosen based on the lowest quasi-Akaike Information Criterion. Differences in cost trajectories by amputation group were tested by inclusion of an amputation status by time interaction term in the model. Models with significant interaction terms $(p \leq 0.05)$ were stratified by amputation status.

\section{Adjusted Total Cost}

Total cost averaged over years of follow-up for each Veteran was modeled using general linear models (GLMs) in STATA with a gamma distribution and log-link. Separate models were then run for psychiatry, pharmacy, prosthetics, 
and rehabilitation cost categories. Interactions between amputation status and significant parameters were tested $(p \leq 0.05)$ and models stratified by significant effect modifiers $(p \leq 0.05)$.

For cost categories with more than 10 percent missing data, costs were imputed based on regression models using the covariates described previously. GLM models were then re-run with imputed costs to examine whether there was any difference with respect to the effect or significance level of each covariate.

\section{RESULTS}

There was an average of $5.3 \mathrm{yr}$ of follow-up per patient. The median age at the time of injury was $24 \mathrm{yr}$ (mean age: $25 \mathrm{yr}$; range: 19-49). The majority of patients were male (98\%), with a similar number of deployments among Veterans with lower-limb injury and unilateral or bilateral lower-limb amputation(s) (Table 1). Amputees were more likely to have blast-related injuries $(p<$ 0.001). Those with bilateral lower-limb amputations had the lowest prevalence of PTSD, the highest prevalence of TBI, the highest ISS, and were more likely to be injured during 2006-2008 ( $p<0.001$ for all).

\section{Missing Cost Data}

There were $73(8 \%)$ observations with missing VA data (including cost). Of these, the majority of missing observations were either in the limb injury $(n=41)$ or unilateral lower-limb amputee group $(n=30)$. There were an additional 60 observations with missing psychiatry cost data, with 45 observations (75\%) missing from those with unilateral lower-limb amputation. Of the 113 missing pharmacy cost records, $85(75 \%)$ were also from those in the unilateral lower-limb amputation group. Of the 87 missing prosthetics cost data, 51 (59\%) were from the limb injury group. Finally, 60 observations were missing rehabilitation cost data, 29 (48\%) of which were missing from among those with limb injury and 27 (45\%) missing from among those with unilateral amputation.

\section{Unadjusted Cost}

Unadjusted mean annual cost per person by year in the VA (first through eighth year) is shown in Figure 1. In addition to the four cost categories (mentioned previously), all remaining outpatient costs were included in the "Other" category (Figure 1). Among Veterans with lower-limb injuries, annual cost peaked in the first year in the VA and declined thereafter (Figure 1). Among those with lower-limb amputation(s), annual costs peaked a few years after entry into the VA and were relatively sustained over the follow-up period. Prosthetics accounted for more than 50 percent of annual cost among those with unilateral or bilateral lower-limb amputation(s).

Unadjusted mean annual costs per person with 95 percent confidence intervals [CIs] from the first through eighth years are shown in Table 2. Among Veterans with lower-limb injuries, the highest annual per person cost was

Table 1.

Baseline characteristics.

\begin{tabular}{|c|c|c|c|}
\hline Variable & $\begin{array}{c}\text { Nonamputee } \\
(n=170)\end{array}$ & $\begin{array}{l}\text { Unilateral Lower } \\
\quad(n=460)\end{array}$ & $\begin{array}{c}\text { Bilateral Lower } \\
\quad(n=153)\end{array}$ \\
\hline PTSD, $n(\%)^{*}$ & $105(62)$ & $238(52)$ & $46(30)$ \\
\hline Age, Mean \pm SD & $24.4 \pm 5.1$ & $25.8 \pm 5.6$ & $25.0 \pm 5.0$ \\
\hline $\mathrm{ISS}$, Mean $\pm \mathrm{SD}^{*}$ & $14.5 \pm 9.0$ & $15.0 \pm 9.0$ & $22.0 \pm 11.0$ \\
\hline No. Deployments, Mean (Range) & $2(1-8)$ & $1(1-13)$ & $1(1-6)$ \\
\hline IED/Blast & $115(68)$ & $405(88)$ & $146(95)$ \\
\hline Gunshot Wound & $43(25)$ & $22(5)$ & $2(1)$ \\
\hline Other & $12(7)$ & $33(7)$ & $5(3)$ \\
\hline Injury During Surge, $n(\%)$ & $77(30)$ & $219(48)$ & $46(83)$ \\
\hline Inpatient Hospital Stay, $n(\%)$ & $47(28)$ & $103(22)$ & $38(25)$ \\
\hline
\end{tabular}

${ }^{*} p<0.001$.

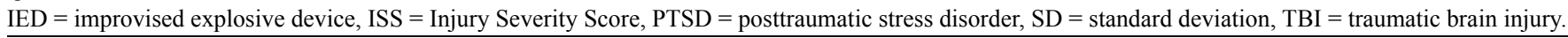




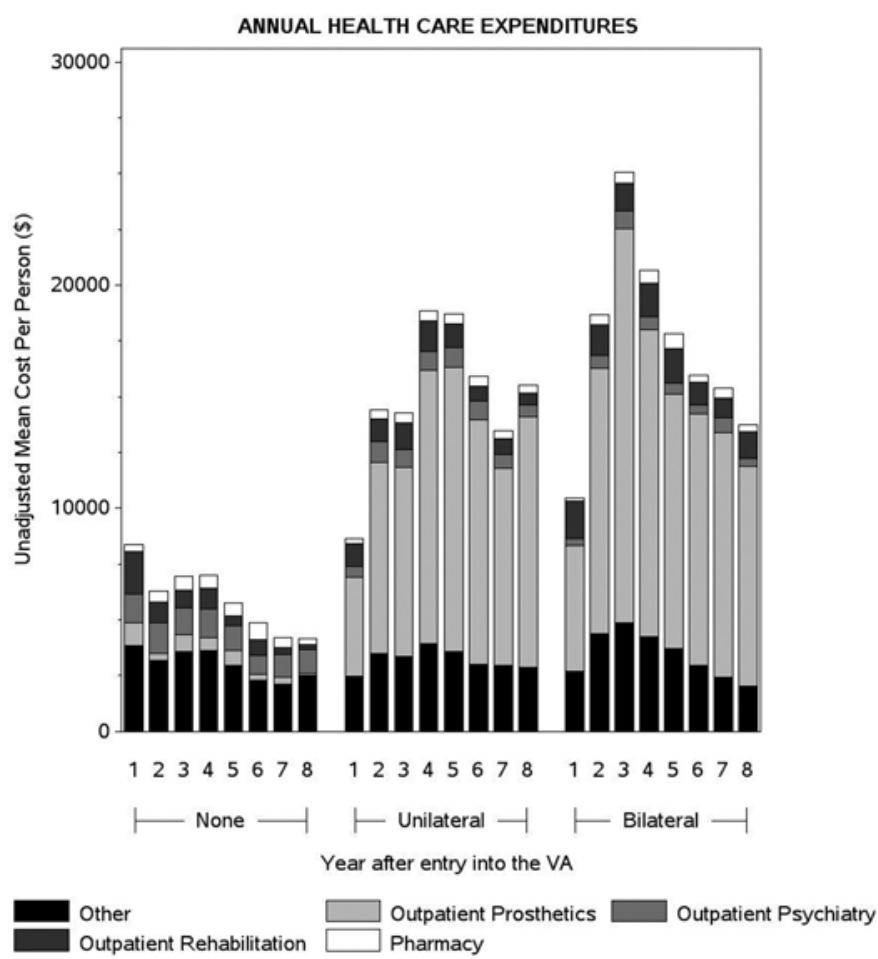

Figure 1.

Among Veterans with lower-limb amputations, annual costs peaked 2-6 yr after entry into Department of Veterans Affairs (VA) $(p<0.001$ for both unilateral and bilateral groups, repeated measures) and remained relatively sustained thereafter, comparable to first year in VA.

$\$ 7,800(95 \% \mathrm{CI}=\$ 6,400-\$ 9,200)$ in the first year. For those with unilateral and bilateral lower-limb amputation(s), the highest annual costs were $\$ 18,800(95 \% \mathrm{CI}=$ $\$ 14,700-\$ 22,900)$ in the fourth year and $\$ 25,000$ (95\% CI $=\$ 19,500-\$ 30,600)$ in the third year, respectively.
Unadjusted mean total costs per person per year are shown in Figure 2. Total cost significantly increased by amputation status $(p<0.001)$ (Figure 2(e)). In comparison with Veterans with lower-limb injuries, total cost was more than 2 times higher for those with lower-limb amputation(s). Cost for prosthetics (including durable medical equipment and orthotics) was 7-9 times higher among Veterans with lower-limb amputation(s) $(p<$ $0.001)$. Amputation status was not associated with pharmacy cost and rehabilitation cost; amputation status was significantly associated with decreased psychiatric cost $(p<0.01)$.

\section{Adjusted Annual Cost}

Annual cost was then modeled as a repeated measure over the $8 \mathrm{yr}$ of follow-up, adjusting for PTSD, TBI, age, number of deployments, ISS, Injury Year, and hospitalization; changes from the first year are shown in Table 3. For those with limb injuries, costs declined in comparison to the first year and were approximately 50 percent less by the fifth year ( $p<0.05$ for all years) (Table 3 ).

For those with unilateral lower-limb amputation, costs were twice as high in the fourth and fifth years $(p<$ 0.001 for both) compared with the first year, remaining 40 to 70 percent higher in comparison thereafter $(p<0.01$ for all years). Among Veterans with bilateral amputations, cost approximately doubled in the third and fourth years ( $p<0.001$ for both) and remained higher in the fifth year $(p<0.01)$. In the sixth, seventh, and eighth years, costs remained comparable to the first year. However, we note these results should be interpreted with caution because of declining sample sizes in the latter years.

Table 2.

Average annual cost (with 95\% confidence interval [CI]) per person in 2012 U.S. dollars by year in Department of Veterans Affairs.

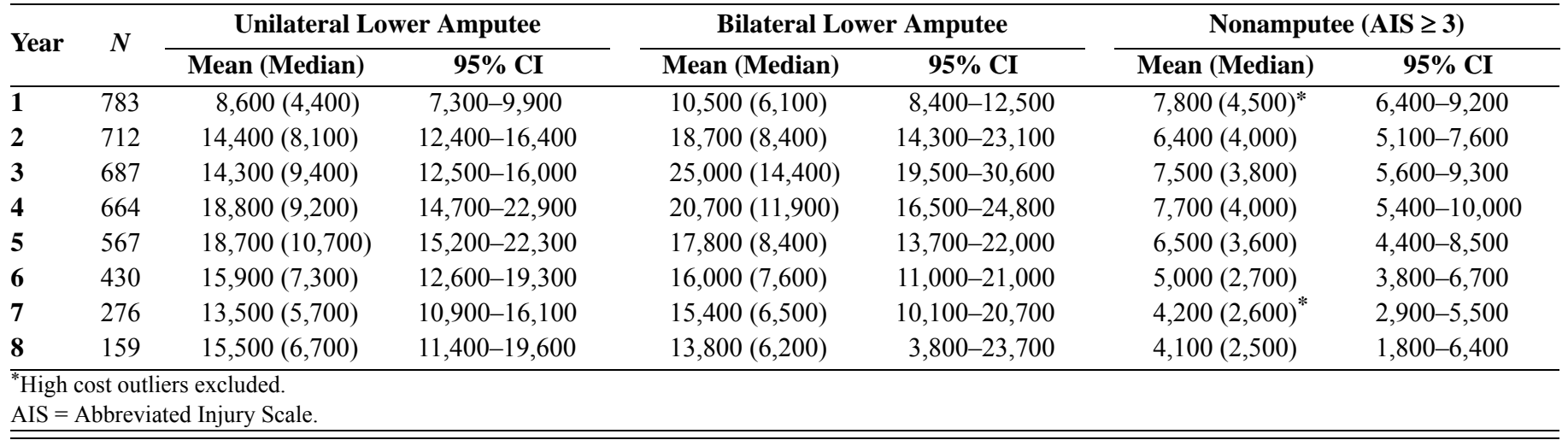




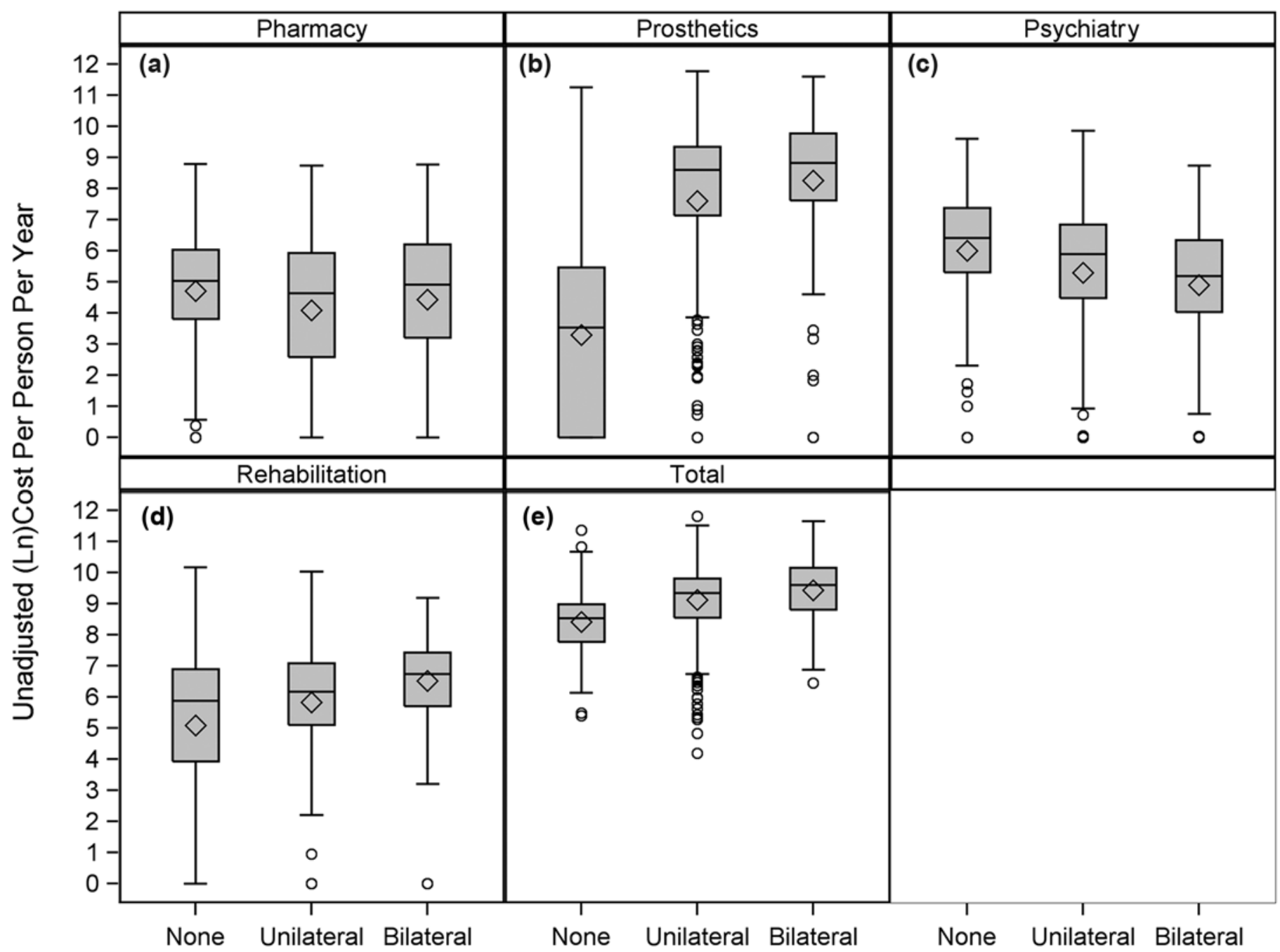

Figure 2.

Unadjusted costs per person averaged over follow-up period for those with lower-limb injury (no amputation) and unilateral or bilateral lower-limb amputation(s) for (a) pharmacy, (b) prosthetics, (c) psychiatry, (d) rehabilitation, and (e) total are shown here. Ln annual cost is shown for clarity; average dollar costs are listed below. Total cost (e) increased by amputation status ( $p<0.01)$ : $\$ 7,200(95 \%$ confidence interval $[\mathrm{Cl}]=\$ 5,800-\$ 8,500), \$ 14,700(95 \% \mathrm{Cl}=\$ 13,300-\$ 16,100)$, and $\$ 18,700(95 \% \mathrm{Cl}=\$ 15,900-\$ 21,500)$ for nonamputees and unilateral and bilateral lower-limb amputees, respectively. Pharmacy costs (a) did not significantly differ by amputation status: $\$ 500$ (95\% Cl = \$360-\$630), \$470 (95\% Cl = \$390-\$560), and \$520 (95\% Cl = \$370-\$670) for nonamputees and unilateral and bilateral lower-limb amputees, respectively. Prosthetics costs (b) increased by amputation status $(p<0.001)$ : $\$ 1,400(95 \% \mathrm{Cl}=\$ 77-\$ 2,700)$, $\$ 9,700(95 \% \mathrm{Cl}=\$ 8,400-\$ 11,000)$, and $\$ 12,700(95 \% \mathrm{Cl}=\$ 10,000-\$ 15,400)$ for nonamputees and unilateral and bilateral lower-limb amputees, respectively. Psychiatry costs (c) decreased by amputation status $(p<0.01)$ : $\$ 1,200(95 \% \mathrm{Cl}=\$ 990-\$ 1,400), \$ 880$ (95\% $\mathrm{Cl}=\$ 750-\$ 1,000)$, and $\$ 580$ (95\% Cl = \$420-\$740) for nonamputees and unilateral and bilateral lower-limb amputees, respectively. Rehabilitation costs (d) did not significantly differ by amputation status: $\$ 1,400(95 \% \mathrm{Cl}=\$ 890-\$ 1,900), \$ 1,100(95 \% \mathrm{Cl}=\$ 950-$ $\$ 1,300)$, and $\$ 1,500(95 \% \mathrm{Cl}=\$ 1,200-\$ 1,800)$ for nonamputees and unilateral and bilateral lower-limb amputees, respectively.

Aside from amputation status, PTSD was the strongest predictor of annual costs ( $p<0.001$, results not shown) followed by a history of hospital admission $(p<0.001$, results not shown) and ISS ( $p=0.003$, results not shown).

\section{Adjusted Total Cost}

A GLM with a gamma distribution and log-link was used to estimate adjusted effects of amputation status and covariates on total cost averaged over the years of 
Table 3.

Change in annual cost from first year in Department of Veterans Affairs: exponentiated regression coefficients (generalized estimating equation).

\begin{tabular}{|c|c|c|c|c|c|c|}
\hline \multirow[b]{2}{*}{ Year } & \multicolumn{2}{|c|}{ Unilateral Amputee } & \multicolumn{2}{|c|}{ Bilateral Amputee } & \multicolumn{2}{|c|}{ Nonamputee AIS $\geq 3$} \\
\hline & $n$ & $\begin{array}{l}\text { Regression } \\
\text { Coefficient }\end{array}$ & $\boldsymbol{n}$ & $\begin{array}{l}\text { Regression } \\
\text { Coefficient }\end{array}$ & $n$ & $\begin{array}{l}\text { Regression } \\
\text { Coefficient }\end{array}$ \\
\hline 1 & 460 & Ref & 153 & Ref & 170 & Ref \\
\hline 2 & 419 & $1.50^{*}$ & 146 & $1.62^{\dagger}$ & 147 & $0.65^{\dagger}$ \\
\hline 3 & 406 & $1.48^{*}$ & 143 & $2.11^{*}$ & 138 & $0.70^{\dagger}$ \\
\hline 4 & 399 & $2.02^{*}$ & 138 & $1.72^{*}$ & 127 & $0.67^{\dagger}$ \\
\hline 5 & 344 & $1.90^{*}$ & 120 & $1.56^{\dagger}$ & 103 & $0.51^{*}$ \\
\hline 6 & 263 & $1.61^{\dagger}$ & 85 & 1.18 & 82 & $0.48^{*}$ \\
\hline 7 & 187 & $1.39^{\dagger}$ & 43 & 1.01 & 46 & $0.47^{\dagger}$ \\
\hline 8 & 118 & $1.70^{\dagger}$ & 19 & 0.87 & 22 & $0.48^{\ddagger}$ \\
\hline $\begin{array}{l}{ }^{*} p \leq 0.0 \\
t^{\prime} p \leq 0.0 \\
{ }^{2} p \leq 0.0 \\
\text { AIS }=A\end{array}$ & & & & & & \\
\hline
\end{tabular}

follow-up. Each cost category (psychiatry, pharmacy, prosthetics, and rehabilitation) was then modeled separately. Exponentiated $\beta$ coefficients and 95 percent CIs from the models are shown in Table 4. The effects of amputation status on cost stratified by significant effect modifiers are shown in Table 5.

There was an approximate 72 percent increase in total cost by amputation status $(95 \% \mathrm{CI}=1.51-1.95, p<$ $0.001)$ and a 62 percent increase in cost with PTSD $(95 \%$ $\mathrm{CI}=1.39-1.89, p<0.001)$ (Table 4). Total cost increased 13 percent $(95 \% \mathrm{CI}=1.04-1.23, p<0.01)$ by ISS category and 41 percent $(95 \% \mathrm{CI}=1.19-1.68, p<0.001)$ with hospitalization (Table 4). However, there was also significant interaction between amputation status and PTSD ( $p=0.03$, interaction term). Effect of amputation was $1.50(95 \% \mathrm{CI}=1.24-2.82)$ without PTSD compared with $2.03(95 \% \mathrm{CI}=1.73-2.38, p<0.001)$ with PTSD (Table 5). Less than 10 percent of observations had missing cost data; these observations were excluded.

\section{Psychiatry Costs}

As shown in Table 4, there was a 23 percent decrease in total psychiatry costs by amputation status $(p<0.01)$. There was a notable 3.42-fold increase in psychiatry costs with PTSD $(p<0.001)$. Costs increased 27 percent by Injury Year $(p=0.03)$ and 63 percent by hospitalization $(p<0.001)$. There were less than 10 percent of observations with missing psychiatry cost data; modeling was not repeated using imputed data.

\section{Pharmacy Costs}

A diagnosis of PTSD was associated with a more than 2-fold increase in total pharmacy costs (Table 4; $p<$ 0.001 ). Pharmacy costs also increased by 30 percent with increasing ISS category $(p<0.001)$. With imputed estimates for missing pharmacy costs, the effect of PTSD and ISS were attenuated to a 14 and 7 percent increase, respectively, and hospitalization was associated with a 16 percent increase in pharmacy costs (data not shown).

\section{Prosthetics Costs}

Amputation status contributed to a 3.12-fold increase $(p<0.001)$ and PTSD contributed to a 57 percent increase $(p<0.01)$ in total prosthetics costs. However, there was also a strong interaction between amputation and a diagnosis of PTSD $(p=0.01)$. While there was a 2.22 -fold increase in prosthetics costs by amputation status without PTSD, there was a 5.04-fold increase by amputation status with PTSD ( $p<0.001$ for both; Table $5)$. With imputed prosthetics costs, the effects of amputation were attenuated to a 2-fold increase; a similar interaction with PTSD was observed $(p=0.02$, interaction term; results not shown).

\section{Rehabilitation Costs}

There was no statistically significant difference in total rehabilitation costs by amputation status. ISS category, Injury Year, and history of hospitalization were associated with an 18 percent $(p<0.01), 61$ percent $(p<$ $0.001)$, and 72 percent $(p<0.001)$ increase in annual 
rehabilitation costs, respectively (Table 4). There were less than 10 percent of observations with missing data.

\section{DISCUSSION}

To our knowledge, this study is one of the first to quantify long-term outpatient costs at the VA over approximately 5 yr per patient among Veterans who had serious limb injuries in the Iraq and Afghanistan conflicts. We compared patients with lower-limb amputation(s) to individuals with serious lower-limb injuries (no amputation). Among Veterans with lower-limb amputation(s), annual outpatient costs were more than 2 times higher, peaking 2-5 yr after entry into the VA. More than 50 percent of outpatient costs came from prosthetics (and other durable medical equipment), with annual prosthetics costs 7-9 times higher following amputation in comparison with Veterans with limb injuries.

Given ongoing advances in technology, such as the use of new materials and development of neuroprosthetics, future costs for prosthetics are likely to accelerate [26]. Approximately 50 percent of all limb prostheses are supplied by Government insurers, including Medicaid, Medicare, and the VA. Costs for these devices vary widely, from under $\$ 10,000$ for more basic walking devices to more than $\$ 30,000$ for computer-assisted devices [27].

The present results provide an important first step toward projecting VA outpatient costs, particularly prosthetics costs, for patients who sustained the most serious combat-related limb injuries in Iraq and Afghanistan. To fully understand the long-term costs associated with state-of-the-art limb prosthetics, more research is needed to document the lifespan, durability, and maintenance issues associated with these devices.

Moreover, while amputation status was the main driver of prosthetics costs, there was a notable 5.04-fold increase in prosthetics costs by amputation status with a PTSD diagnosis. Consistent with our findings, Veterans from the war in Kosovo with transtibial amputation(s) and PTSD had lower levels of functional rehabilitation compared with those without PTSD [28], suggesting that recovery may be slower (and/or more complicated) for patients with PTSD. Nevertheless, medical care and rehabilitation may be more costly for these patients, requiring new or adjunctive therapeutic approaches and perhaps additional training for medical providers and support staff. Previous research has
Table 4.

Change in cost by amputation status and covariates: exponentiated regression coefficient and 95 percent confidence intervals (CIs) (general linear model [gamma distribution and log-link]). Boldface indicates statistical significance.

\begin{tabular}{|c|c|c|}
\hline Model Covariates & $\begin{array}{l}\text { Regression } \\
\text { Coefficient }\end{array}$ & $95 \%$ CI \\
\hline \multicolumn{3}{|l|}{ Total } \\
\hline Amputation Status ${ }^{* \dagger}$ & 1.72 & $1.51-1.95$ \\
\hline PTSD $^{* \dagger}$ & 1.62 & $1.39-1.89$ \\
\hline TBI & 0.96 & $0.81-1.14$ \\
\hline Age $\geq 27 \mathrm{yr}$ & 0.98 & $0.83-1.16$ \\
\hline ISS & 1.13 & $1.04-1.23$ \\
\hline Injury Year & 1.03 & $0.87-1.21$ \\
\hline Inpatient Hospital Stay ${ }^{*}$ & 1.41 & $1.19-1.68$ \\
\hline No. Deployments & 0.94 & $0.85-1.04$ \\
\hline \multicolumn{3}{|l|}{ Psychiatry } \\
\hline Amputation Status & 0.77 & $0.66-0.90$ \\
\hline PTSD $^{*}$ & 3.42 & $2.78-4.22$ \\
\hline TBI & 0.82 & $0.66-1.03$ \\
\hline Age $\geq 27 \mathrm{yr}$ & 0.91 & $0.73-1.14$ \\
\hline ISS & 1.09 & $0.98-1.21$ \\
\hline Injury Year ${ }^{\S}$ & 1.27 & $1.02-1.57$ \\
\hline Inpatient Hospital Stay ${ }^{*}$ & 1.63 & $1.30-2.06$ \\
\hline No. Deployments & 1.04 & $0.91-1.19$ \\
\hline \multicolumn{3}{|l|}{ Pharmacy } \\
\hline Amputation Status & 0.96 & $0.78-1.20$ \\
\hline PTSD $^{*}$ & 2.16 & $1.60-2.92$ \\
\hline TBI & 1.04 & $0.76-1.42$ \\
\hline Age $\geq 27 \mathrm{yr}$ & 1.02 & $0.74-1.41$ \\
\hline ISS & 1.30 & 1.11-1.52 \\
\hline Injury Year & 1.18 & $0.88-1.59$ \\
\hline Inpatient Hospital Stay ${ }^{*}$ & 2.05 & $1.49-2.82$ \\
\hline No. Deployments & 1.03 & $0.84-1.26$ \\
\hline \multicolumn{3}{|l|}{ Prosthetic } \\
\hline Amputation Status ${ }^{* \dagger}$ & 3.12 & $2.31-4.23$ \\
\hline $\operatorname{PTSD}^{\dagger \dagger}$ & 1.57 & $1.19-2.06$ \\
\hline TBI & 0.90 & $0.67-1.22$ \\
\hline ISS & 0.83 & $0.62-1.11$ \\
\hline Age $\geq 27 \mathrm{yr}$ & 1.20 & $0.89-1.62$ \\
\hline Injury Year & 1.06 & $0.91-1.24$ \\
\hline Inpatient Hospital Stay & 1.00 & $1.00-1.26$ \\
\hline No. Deployments & 0.95 & $0.79-15$ \\
\hline \multicolumn{3}{|l|}{ Rehabilitation } \\
\hline Amputation Status & 0.99 & $0.83-1.18$ \\
\hline PTSD & 1.15 & $0.92-1.43$ \\
\hline TBI & 1.17 & $0.92-1.49$ \\
\hline Age $\geq 27 \mathrm{yr}$ & 0.93 & $0.73-1.18$ \\
\hline $\mathrm{ISS}^{+}$ & 1.18 & $1.05-1.33$ \\
\hline Injury Year $^{*}$ & 1.61 & $1.28-2.04$ \\
\hline Inpatient Hospital Stay ${ }^{*}$ & 1.72 & $1.34-2.21$ \\
\hline No. Deployments & 0.97 & $0.84-1.13$ \\
\hline \multicolumn{3}{|c|}{ 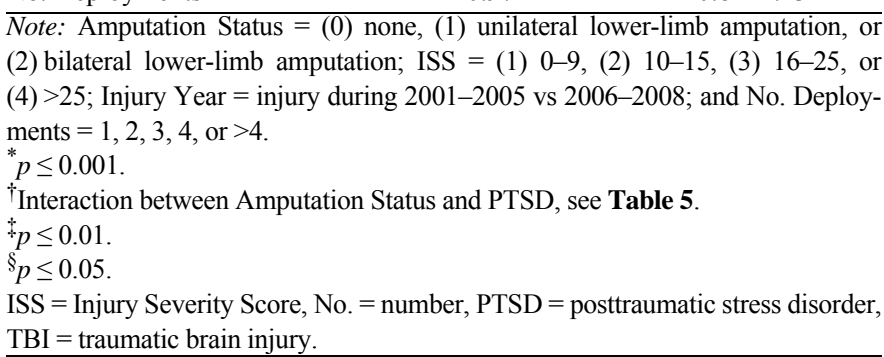 } \\
\hline
\end{tabular}


Table 5.

Effect of amputation status on change in annual total and prosthetic cost, stratified by posttraumatic stress disorder (PTSD): exponentiated regression coefficient and 95 percent confidence intervals (CIs) (general linear model).

\begin{tabular}{lcc}
\hline Model Covariates & $\begin{array}{c}\text { Regression } \\
\text { Coefficient }\end{array}$ & 95\% CI \\
\hline Total Cost & 1.50 & $1.24-1.82$ \\
Without PTSD $^{*}$ & 2.03 & $1.73-2.38$ \\
With PTSD $^{*}$ & & \\
Prosthetic Cost & 2.22 & $1.52-3.22$ \\
Without PTSD & 5.04 & $3.00-8.26$ \\
With PTSD & & \\
\hline${ }^{*} p \leq 0.001$. & & \\
\hline
\end{tabular}

shown that utilization rates of general outpatient and inpatient VA care are almost doubled among Veterans with a PTSD diagnosis compared with those with no mental health diagnosis [29]. While this may partly account for higher costs within and outside of the mental health domain, a 5.04-fold increase in prosthetics costs is not likely to be driven by utilization alone. Whether Veterans with limb amputation(s) and PTSD have increased use of prosthetics is not known at this time.

In this study, PTSD was also associated with a 3.42and 2.16-fold increase in psychiatry and pharmacy costs, respectively. This finding may be driven by increased utilization and/or comorbid diagnoses, such as substance abuse or depression. In addition, multiple medications or more costly (or newer classes of) medications may be used to manage the complex psychological symptoms experienced by patients with PTSD.

Of note, we found that Veterans with bilateral lowerlimb amputations had the lowest prevalence of PTSD and had the lowest costs associated with psychiatric care, despite higher ISS scores and increased likelihood of injury during the later years of the conflict in Iraq. Similarly, Veterans from Croatia without disabling injuries had higher rates of PTSD than those with permanently disabling injuries [30]. It is possible that progressive postinjury care may reduce the likelihood of developing PTSD. An initial study found lower rates of PTSD in the short term among trauma Veterans who received morphine shortly after injury than patients who received fentanyl [31]. However, recent analysis suggested that this difference was not sustained over a longer follow-up period [32]. Thus, other field management practices such as level of sedation or perhaps more intensive early man- agement, including psychiatric treatment and psychological support, may reduce the risk of PTSD. Patients with bilateral lower-limb amputations may also have fewer PTSD-related psychological symptoms given the challenge of physical recovery and rehabilitation. A recent cross-sectional postdeployment study of Veterans from Iraq found number of deployments directly related to the risk of PTSD [33].

Several other combat-related variables were also associated with cost across multiple healthcare categories. Pharmacy and rehabilitation costs increased with higher ISS; rehabilitation cost was also associated with Injury Year (injury during later years of the Iraq and Afghanistan conflicts). While these observations make intuitive sense, future research should clarify reasons for these observations. Hospitalization was also associated with increased total cost and psychiatry and rehabilitation costs. This may be partially attributed to a marginal association between hospitalization and PTSD $(p=0.07$, results not shown); inpatient admission is also likely associated with a more complex set of patients (with or without PTSD), with healthcare utilization extending into the outpatient period. Finally, though TBI was not a predictor of cost, it should be noted that we did not differentiate between mild, moderate, or severe TBI.

Previous modeling of imputed costs from survey data of Veterans from Iraq and Afghanistan estimated $5 \mathrm{yr}$ prosthetics costs of more than $\$ 200,000$ following unilateral lower-limb amputation(s) [14]. The present study included a larger sample and actual cost data, but found lower overall costs than the previous survey study. These differences in overall costs may result from differences in study design. Our use of military registries identified nearly all recent combat amputees, while results from the previous survey study may be affected by sampling bias due to relatively high rates of nonresponse to surveys. However, our results probably underestimate the cost of prosthetics as vendors outside the VA also provide services [34]. At this time, we do not have access to the National Prosthetics Patient Database, probably the most comprehensive repository for prosthetics costs. Finally, purchased care data available through the Corporate Data Warehouse do not completely reflect VA-wide fee-based care and were not included in this analysis. We understand that this may lead to underestimation of costs, particularly those pertaining to prosthetics, rehabilitation, and home care. However, results of our study are consistent with cost analysis from the Lower Extremity Assessment Project (LEAP), a cohort 
of 601 civilian adults with serious limb injuries. In the LEAP study, projected lifetime healthcare cost, including prosthetics, was approximately 3 times higher among those with amputation(s) compared with those with limb reconstruction [35].

The strength of the present study was that we identified and included 92 percent of the original EMED amputee cohort within the VA system and tracked their outpatient clinic utilization and costs for an average of $5.3 \mathrm{yr}$ of follow-up. As part of the collaborative effort, we were also able to use covariates specific to combat contained in the EMED database (e.g., ISS, number of deployments).

However, we also note that results are specific to the VA and may not generalize to patients who did not sustain combat injuries or patients with upper-limb amputations. This initial study is also limited in scope because it excluded additional outpatient cost categories grouped as "Other" (e.g., primary care). Further analyses on inpatient, surgical, and prosthetic costs and utilization trends are also required. In addition, differences between early and late amputees were not studied here [3], and costs in later years may be skewed by high usage among few amputees. We also note that the difference between transtibial and transfemoral amputation may also result in price differentials and should be considered in future research. Our preliminary analysis suggested that, for those with unilateral lower-limb amputation, there was no such significant difference in cost once adjusted for PTSD (results not shown). Unfortunately, data on anatomical location of amputation was not complete for bilateral amputations at this time. Because we were interested in understanding how costs changed after entry into the VA system, the analysis was not done by VA fiscal year. In order to be classified with PTSD, we required a minimum of two diagnoses for PTSD. This selection criterion likely avoided misdiagnoses and increased correct identification of PTSD cases included in our study. However it may have resulted in a sample of PTSD patients with more complicated treatment requirements and higher costs. Finally, we noted attenuated results for pharmacy costs with imputed data. This category also had the most missing data that may be captured elsewhere.

\section{CONCLUSIONS}

Compared with Veterans with combat-related, serious lower-limb injuries without amputation, annual out- patient cost was more than 2-fold higher among Veterans with lower-limb amputation(s). Annual prosthetic cost was 7-9 times higher among Veterans with lower-limb amputation(s) compared with individuals with serious limb injury. While Veterans with lower-limb injuries had diminishing costs after entry into the VA, costs among Veterans with lower-limb amputation(s) doubled in the first 3-5 yr and were sustained thereafter in comparison to the first year. These sustained costs came primarily from the cost of prosthetics and other specialized types of care. PTSD was a strong predictor of increased costs for prosthetics, pharmacy, and psychiatric care. This highlights the impact of PTSD across multiple domains of health and the importance of adequate PTSD diagnosis, treatment, and support for returning military personnel.

\section{ACKNOWLEDGMENTS}

\section{Author Contributions:}

Study concept and design: V. Bhatnagar, T. Melcer.

Acquisition of data: V. Bhatnagar, E. Richard, M. Galarneau.

Analysis and interpretation of data: V. Bhatnagar, E. Richard, J. Walker.

Drafting of manuscript: V. Bhatnagar, E. Richard, T. Melcer.

Critical revision of manuscript for important intellectual content:

J. Walker, M. Galarneau.

Statistical analysis: V. Bhatnagar, E. Richard.

Study supervision: V. Bhatnagar, M. Galarneau.

Obtained funding: T. Melcer, M. Galarneau.

Administrative, technical, or material support: J. Walker.

Financial Disclosures: The authors have declared that no competing interests exist.

Funding/Support: This material was based on work supported by the U.S. Navy Bureau of Medicine and Surgery under the Wounded, Ill, and Injured/Psychological Health/Traumatic Brain Injury Program (work unit No. 61110).

Additional Contributions: The authors thank VA and VA Informatics and Computing Center for support of this project. This study, and the manuscript itself, benefited greatly from advice and assistance from the clinicians, technical writers, database analysts, and programmers working on the EMED project at the NHRC, including Carrie Brown, Amber Dougherty, Judy Dye, Natella Feinstein, Peggy Han, Hoa Ly, Lisa O’Mara, Gerry Pang, and Kimberly Quinn.

Institutional Review: This research has been conducted in compliance with all applicable Federal regulations governing the protection of human subjects in research (protocols NHRC.2007.0016 and VA H130271). This study was approved by the VA San Diego Research and Development Service; University of California, San Diego; and NHRC Institutional Review Boards.

Participant Follow-Up: The authors have no plans to notify the study subjects of the publication of this article because of a lack of contact information. 
Disclaimer: The views expressed in this article are those of the authors and do not necessarily reflect the official policy or position of the Department of the Navy, Department of Defense, or the U.S. Government.

\section{REFERENCES}

1. Geiling J, Rosen JM, Edwards RD. Medical costs of war in 2035: Long-term care challenges for veterans of Iraq and Afghanistan. Mil Med. 2012;177(11):1235-44. [PMID:23198496] http://dx.doi.org/10.7205/MILMED-D-12-00031

2. Hoge CW, Terhakopian A, Castro CA, Messer SC, Engel CC. Association of posttraumatic stress disorder with somatic symptoms, health care visits, and absenteeism among Iraq war veterans. Am J Psychiatry. 2007;164(1): 150-53. [PMID:17202557] http://dx.doi.org/10.1176/ajp.2007.164.1.150

3. Melcer T, Sechriest VF, Walker J, Galarneau M. A comparison of health outcomes for combat amputee and limb salvage patients injured in Iraq and Afghanistan wars. J Trauma Acute Care Surg. 2013;75(2 Suppl 2):S247-54.

[PMID:23883916] http://dx.doi.org/10.1097/TA.0b013e318299d95e

4. Melcer T, Walker GJ, Galarneau M, Belnap B, Konoske P. Midterm health and personnel outcomes of recent combat amputees. Mil Med. 2010;175(3):147-54.

[PMID:20358702] http://dx.doi.org/10.7205/MILMED-D-09-00120

5. Pugh MJ, Finley EP, Copeland LA, Wang CP, Noel PH, Amuan ME, Parsons HM, Wells M, Elizondo B, Pugh JA. Complex comorbidity clusters in OEF/OIF veterans: The polytrauma clinical triad and beyond. Med Care. 2014;52(2):172-81. [PMID:24374417] http://dx.doi.org/10.1097/MLR.0000000000000059

6. Cross JD, Ficke JR, Hsu JR, Masini BD, Wenke JC. Battlefield orthopaedic injuries cause the majority of long-term disabilities. J Am Acad Orthop Surg. 2011;19(Suppl 1):S1-7. [PMID:21304041]

7. Belisle JG, Wenke JC, Krueger CA. Return-to-duty rates among US military combat-related amputees in the global war on terror: Job description matters. J Trauma Acute Care Surg. 2013;75(2):279-86. [PMID:23887560] http://dx.doi.org/10.1097/TA.0b013e31829bb777

8. Fitzpatrick KF, Pasquina PF. Overview of the rehabilitation of the combat casualty. Mil Med. 2010;175(7 Suppl):13-17. [PMID:23634473] http://dx.doi.org/10.7205/MILMED-D-10-00159

9. Lew HL, Otis JD, Tun C, Kerns RD, Clark ME, Cifu DX. Prevalence of chronic pain, posttraumatic stress disorder, and persistent postconcussive symptoms in OIF/OEF veter- ans: Polytrauma clinical triad. J Rehabil Res Dev. 2009; 46(6):697-702. [PMID:20104399]

http://dx.doi.org/10.1682/JRRD.2009.01.0006

10. Potter BK, Scoville CR. Amputation is not isolated: An overview of the US Army Amputee Patient Care Program and associated amputee injuries. J Am Acad Orthop Surg. 2006;14(10 Spec No.):S188-90. [PMID:17003197]

11. Armed Forces Health Surveillance Center. Deployment related conditions of special surveillance interests, U.S. Armed Forces, by month and service January 2003December 2012. MSMR. 2013;20(1):17-19.

12. Pittman JO, Goldsmith AA, Lemmer JA, Kilmer MT, Baker DG. Post-traumatic stress disorder, depression, and health-related quality of life in OEF/OIF veterans. Qual Life Res. 2012;21(1):99-103. [PMID:21516356] http://dx.doi.org/10.1007/s11136-011-9918-3

13. Krueger CA, Wenke JC, Ficke JR. Ten years at war: Comprehensive analysis of amputation trends. J Trauma Acute Care Surg. 2012;73(6 Suppl 5): S438-44. [PMID:23192067] http://dx.doi.org/10.1097/TA.0b013e318275469c

14. Blough DK, Hubbard S, McFarland LV, Smith DG, Gambel JM, Reiber GE. Prosthetic cost projections for servicemembers with major limb loss from Vietnam and OIF/OEF. J Rehabil Res Dev. 2010;47(4):387-402.

[PMID:20803406]

http://dx.doi.org/10.1682/JRRD.2009.04.0037

15. The Congress of the United States Congressional Budget Office. A CBO Study: The Veterans Health Administration's treatment of PTSD and traumatic brain injury among recent combat veterans [Internet]. Washington (DC): CBO; 2012 Feb. Available from: http://www.cbo.gov/sites/ default/files/cbofiles/attachments/02-09-PTSD.pdf

16. Cesur RS, Tekin E. The psychological costs of war: Military combat and mental health. Cambridge (MA): National Bureau of Economic Research; 2011.

17. Masini BD, Waterman SM, Wenke JC, Owens BD, Hsu JR, Ficke JR. Resource utilization and disability outcome assessment of combat casualties from Operation Iraqi Freedom and Operation Enduring Freedom. J Orthop Trauma. 2009;23(4):261-66. [PMID:19318869] http://dx.doi.org/10.1097/BOT.0b013e31819dfa04

18. Ebrahimzadeh MH, Kachooei AR, Soroush MR, Hasankhani EG, Razi S, Birjandinejad A. Long-term clinical outcomes of war-related hip disarticulation and transpelvic amputation. J Bone Joint Surg Am. 2013;95(16):e114. [PMID:23965708] http://dx.doi.org/10.2106/JBJS.L.01160

19. Galarneau MR, Hancock WC, Konoske P, Melcer T, Vickers RR, Walker GJ, Zouris JM. The Navy-Marine Corps Combat Trauma Registry. Mil Med. 2006;171(8):691-97. [PMID:16933807] http://dx.doi.org/10.7205/MILMED.171.8.691 
20. Copes WS, Champion HR, Sacco WJ, Lawnick MM, Keast SL, Bain LW. The Injury Severity Score revisited. J Trauma. 1988;28(1):69-77. [PMID:3123707] http://dx.doi.org/10.1097/00005373-198801000-00010

21. Tohira H, Jacobs I, Mountain D, Gibson N, Yeo A. Comparisons of the outcome prediction performance of injury severity scoring tools using the Abbreviated Injury Scale 90 Update 98 (AIS 98) and 2005 Update 2008 (AIS 2008). Ann Adv Automot Med. 2011;55:255-65. [PMID:22105401]

22. VA Information Resource Center. VIReC Resource guide: VA Corporate Data Warehouse [Internet]. Hines (IL): U.S. Department of Veterans Affairs Health Services Research and Development Service; 2012 Jun. Available from: http:// www.hsrd.research.va.gov/for_researchers/vinci/cdw.cfm

23. U.S. Department of Veterans Affairs. VA Informatics and Computing Infrastructure (VINCI) [Internet]. Washington (DC): U.S. Department of Veterans Affairs; 2012 Jun. Available from:

http://www.hsrd.research.va.gov/for researchers/vinci

24. Barnett PG, Chen S, Wagner TH. Determining the cost of VA care with the average cost method for the 1993-1997 fiscal years [Internet]. Washington (DC): U.S. Department of Veterans Affairs. VA Health Economic Resource Center; 2000 Oct. Available from:

http://www.herc.research.va.gov/files/RPRT 8.pdf

25. U.S. Department of Commerce, Bureau of Economic Analysis. National data: National income and product accounts tables. Table 1.1.9. Implicit Price Deflators for Gross Domestic Product [Internet]. Washington (DC): U.S. Department of Commerce; 2015 Sep. Available from:

http://www.bea.gov/iTable/

iTable.cfm?reqid $=9 \&$ step $=3 \&$ isuri $=1 \& 903=13 \#$ reqid $=9 \&$ s tep $=3$ \& isuri $=1 \& 903=13$

26. Harvey ZT, Potter BK, Vandersea J, Wolf E. Prosthetic advances. J Surg Orthop Adv. 2012;21(1):58-64. [PMID:22381512]

27. Grant McGimpsey G, Bradfo TC. Limb prosthetics services and devices critical unmet need: Market analysis [Internet]. Worcester (MA): Bioengineering Institute Center for Neuroprosthetics, Worcester Polytechnic Institution. Available from: http://www.nist.gov/tip/wp/pswp/upload/ 239 limb_prosthetics services devices.pdf

28. Osmani-Vllasolli T, Hundozi H, Orovcanec N, Krasniqi B, Murtezani A. Rehabilitation outcome following warrelated transtibial amputation in Kosovo. Prosthet Orthot Int. 2014;38(3):211-17. [PMID:23863196] http://dx.doi.org/10.1177/0309364613494084

29. Cohen BE, Gima K, Bertenthal D, Kim S, Marmar CR, Seal KH. Mental health diagnoses and utilization of VA non-mental health medical services among returning Iraq and Afghanistan veterans. J Gen Intern Med. 2010;25(1):

\section{8-24. [PMID:19787409]}

http://dx.doi.org/10.1007/s11606-009-1117-3

30. Delimar D, Sivik T, Korenjak P, Delimar N. The effect of different traumatic experiences on the development of post-traumatic stress disorder. Mil Med. 1995;160(12): 635-39. [PMID:8775392]

31. Holbrook TL, Galarneau MR, Dye JL, Quinn K, Dougherty AL. Morphine use after combat injury in Iraq and posttraumatic stress disorder. N Engl J Med. 2010;362(2):110-17. [PMID:20071700] http://dx.doi.org/10.1056/NEJMoa0903326

32. Melcer T, Walker J, Bhatnagar V, Richard E, Han P, Sechriest V 2nd, Lebedda M, Quinn K, Galarneau M. Glasgow Coma Scale scores, early opioids, and 4-year psychological outcomes among combat amputees. J Rehabil Res Dev. 2014;51(5):697-710. [PMID:25509056] http://dx.doi.org/10.1682/JRRD.2013.06.0143

33. Reger MA, Gahm GA, Swanson RD, Duma SJ. Association between number of deployments to Iraq and mental health screening outcomes in US Army soldiers. J Clin Psychiatry. 2009;70(9):1266-72. [PMID:19689917] http://dx.doi.org/10.4088/JCP.08m04361

34. Smith MW, Su P, Phibbs CS. Matching prosthetics order records in VA National Prosthetics Patient Database to healthcare utilization databases. J Rehabil Res Dev. 2010; 47(8):725-37. [PMID:21110248] http://dx.doi.org/10.1682/JRRD.2009.07.0098

35. MacKenzie EJ, Jones AS, Bosse MJ, Castillo RC, Pollak AN, Webb LX, Swiontkowski MF, Kellam JF, Smith DG, Sanders RW, Jones AL, Starr AJ, McAndrew MP, Patterson BM, Burgess AR. Health-care costs associated with amputation or reconstruction of a limb-threatening injury. J Bone Joint Surg Am. 2007;89(8):1685-92. [PMID:17671005] http://dx.doi.org/10.2106/JBJS.F.01350

Submitted for publication December 1, 2014. Accepted in revised form July 1, 2015.

This article and any supplementary material should be cited as follows:

Bhatnagar V, Richard E, Melcer T, Walker J, Galarneau M. Lower-limb amputation and effect of posttraumatic stress disorder on Department of Veterans Affairs outpatient cost trends. J Rehabil Res Dev. 2015;52(7):827-38. http://dx.doi.org/10.1682/JRRD.2014.11.0288

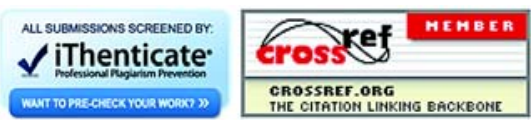

